\title{
Priorities for research in accident and emergency medicine
}

\author{
R. SCOTT \\ Department of Military Surgery, Royal Army Medical College, London
}

The Royal Army Medical College was founded in 1860. The staff included a Professor of Military Medicine, a Professor of Military Surgery, a Professor of Military Hygiene and a Professor of Pathology. The main role of the Professor of Surgery is to participate in the teaching of young medical officers in those aspects of surgery particularly relevant to the military community and also to participate in the education and training of army surgeons. My illustrious predecessor Surgeon General, Sir Thomas Longmore initiated the research activities of the Department of Military Surgery which, with various fallow periods have continued to the present day.

'Research' is a term which can cover a multitude of activities from information gathering at one end of the scale to quite specific scientific laboratory research on the other. In the medical profession it is generally admitted that much of the research carried out in our hospitals is a higher professional training activity. I believe that retrospective and prospective surveys of the management of patients in a department are not only interesting but necesssary if we are to deploy our resources in the most efficient way for the patient's benefit.

Clinical research is more commonly thought of in terms of clinical investigation and the clinical trial has come to dominate the research activities of our major hospitals. To be effective, clinical research needs appropriate facilities and equipment and in my experience the people involved must have sufficient time to set aside from the clinical commitment. Even for individual research projects some sort of organization is required, particularly in these days when most research projects must be vetted by an ethical committee.

I believe that clinical research should be relevant to some practical problem and that it should be productive in that it leads to some change in practice which is ultimately to the benefit of our patients.

\section{Military surgery}

The recent Falklands Campaign provided the Medical Services of the Royal Navy and the Army with a relatively large number of casualties over a short time. The number of

Correspondence: Colonel R. Scott, Department of Military Surgery, Royal Army Medical College, Millbank,

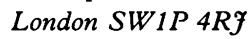


casualties sustained by the security forces and civilians in Northern Ireland from 196 up to the present time is very much greater and they have been caused by a wide variet of injuring devices. We have been interested particularly in injuries caused by militar rifle bullets a surprisingly high proportion of which have been sustained in the region of the head and neck and the thorax. The information on the causes of British fataliti虚 during the Falklands land battle is incomplete but also shows somewhat surprisingtg that penetrating head and chest wounds were responsible for a large proportion of fat injuries. There were a significant number of soldiers who sustained burns but this was mainly due to one notable attack on a troop ship (Jackson et al., 1983).

It is against the background of this experience that we have developed our main programmes of research but unlike the accident and emergency departments we have a $\vec{\nexists}$ additional responsibility to look to the future and attempt to assess what clinicat problems different types of military activity could lead to.

\section{The study of injury}

In relation to the military context where injuries in general are caused by weapons we have in some specific instances studied the mechanism of injury; made some attempts at quantification; aimed some of our research at the prevention of specific types of injur and last, but by no means least looked for improvement in our current methods of treatment.

\section{Mechanism}

Because of our experience in jungle operations, counterinsurgency and various othe⿳亠⿻口丿 types of relatively low intensity operations we have made a special study of the effects ơ the newer types of military rifle bullet. We have studied these using simulants an $\vec{\Phi}$ where it was absolutely essential we have also studied the effects of bullets on anaesthetised animals (Scott, 1983).

The 'shaped charge' is a relatively new type of anti-tank warhead, in which the explosive material is shaped to provide a narrow jet of molten metal which can penetrate. thick steel. We have looked at the physical consequences of such penetration to gain some understanding of the injuries sustained by tank crews. As part of this largi programme we have also looked at what happens to the crew of armoured vehicles whe the vehicle is blown up by a land mine. It would not surprise you to learn that many o\$ the serious injuries caused in this circumstance are blunt injuries of the head, some of which can be prevented by appropriate safety harness. In view of the current publicit about serious injuries sustained by passengers in public vehicles, accident and emerg ency departments may be in a position to show whether some or all of these could alsQ be prevented by appropriate restraining harness or modification of the internal layout of the vehicle.

\section{Quantification}

The Abbreviated Injury Scale has proved to be very useful in assessing the severity of 
injury to patients admitted after road accidents to accident and emergency departments. It gives a base line against which various treatment regimens can be assessed for their effectiveness especially in those patients for whom the prognosis is poor (Bull, 1982). In a selected series of cases of penetrating injury of the trunk sustained by soldiers we considered that the AIS system was unlikely to be helpful but we used another approach to develop a lethality coefficient for organ injury which could have predictive value (Scott, 1976).

There is still a great deal of scope for the use of the computer in this field but it has the drawback that very accurate observations are needed on a large number of patients and considerable familiarity with computer modelling techniques is required before an investigation along these lines can be planned.

\section{Prevention}

The successful use of seat belts in the prevention of injury to the occupants of motor cars involved in road traffic accidents has been well documented in Australia and is being noted in accident and emergency departments throughout the country (Mackay, 1982). I have no doubt that similar reports will emerge in this country over the next few years. As I have indicated many of the injuries sustained during military activity are of similar type and can also be successfully prevented and much of our research on head injury has led to improved bump and impact protection from suitable helmets. We have even had some success in a programme designed to improve protection against penetrating missiles. This programme involved looking in detail at the site of injury, the vulnerability of the injured organs, the usefulness of the various types of protection available and the eventual development of specific protective jackets for the soldier during military activity (Scott, 1976).

\section{Treatment}

From the days of Jean Larrey, military surgeons have been interested in the fate of casualties from the point of wounding to their eventual discharge from hospital and return to duty. Although the accident and emergency department may not have direct control over the management of the casualty at the site of injury and during his transport to hospital there is a growing awareness that the lives of some patients may be saved during this period and for others, especially those with head injury, morbidity may be decreased. Some excellent studies on the effectiveness of resuscitation during this period and on the circulatory disturbances during ambulance transport have been undertaken but there is room for more studies of this type (Macdonald, 1980). There is insufficient information available to make the case for helicopter evacuation of the seriously injured and quite apart from the possible cost we have found in the military context that helicopter transport is not without its own problems. The possible benefit in terms of lives to be saved should be compared with other possible approaches to the problem. This is a fertile field for cooperation between general practitioners, ambulance services and accident and emergency departments. 


\section{Research in the accident and emergency department}

Most of us have been conditioned over the years to think of patient related research in terms of investigation of patho-physiology, or of clinical pharmacology, of the clinica $\mathbb{Q}$ trial of new drugs or of new methods of surgical treatment. The opportunities for this type of clinical research in the accident and emergency department will obviously depend on what patients are admitted. What may start off as a comparatively mundane investigation may lead along quite exciting paths. Some years ago we were distressed by the very high mortality of penetrating head injury in British soldiers in Northern Ireland and began a cooperative investigation with Mr Gordon and Mr Crockard at the्, Royal Victoria Hospital in Belfast. They had found that the prognosis in penetrating head injury was related to the level of consciousness of the patient on arrival at theaccident and emergency department and also found that this level could be related to the $\vec{\omega}$ degree of respiratory difficulty and could sometimes be improved by intermittent他 positive pressure respiration (Gordon \& Crockard, 1974). These observations led on to a pathological investigation which revealed disturbances in the medulla and which mayị eventually point the way to improved management of such patients (Allen et al., 1983). $\widetilde{V}$

Of course there are many opportunities for straightforward trials of treatment and I음 am most impressed by the improvement in treatment of minor burns in casualty departments with the use of silver sulphadiazine, developed as a result of long painstaking, investigations by Jackson et al. (1979) at the Birmingham Accident ${ }^{\mathbb{D}}$ Hospital.

Gas gangrene was a complication most to be feared in penetrating wounds caused by gunshot in military circumstance. The development of current methods of treatmento has a long history extending right back to Ambroise Pare and there are still oppopti tunities in accident and emergency departments for clinical trials of various types of treatment of wounds and particularly of the place of antibiotics in prophylaxis of the contaminated wound. I think it is still not often appreciated how incapacitating some apparently minor wounds are. Some 20 years ago while working at the Birmingham 3 Accident Hospital I discovered to my surprise that infections of the fingers caused more time off work than fractures of the femur for some groups of patients.

Clinical research must be relevant and it must be productive. Any study of patients in 3 the accident and emergency department will presumably be relevant to the work of thatio department. Whether it is likely to be productive depends on a large number of factors.

Medawar has described research as 'the art of the soluble' (1967). Some situations? may seem incapable of solution and may even be overwhelming. Many young doctors have not grasped that the essence of the scientific method is to look at a problem in general and then to select bits of it that are capable of analysis. We should ask medicalo scientists to join with us at looking at clinical problems. The combination of clinician and medical scientists has been very fruitful in the past in the fields of accident and emergency medicine and the medical scientist usually has a clear conception of what is soluble and what is not.

\section{Research in support of higher professional training}

Clinical research is expensive, time consuming and liable to end up with meetings, 
seminars, papers and international travel. Can it be justified in terms of higher professional training when experience shows that the majority of those who have completed an obligatory research year in other disciplines thereafter lose all apparent interest in research? The answer to this question depends on whether you believe that scientific medicine which began with William Harvey in this country 400 years ago is still the answer to the majority of the problems which we encounter in our patients or whether you accept that most of them would be better treated by homeopathy, acupuncture, chiropractice, or other so called 'alternative' forms of medicine. Frankly I cannot see that the injured have much to gain from acupuncture and in my own rather narrow field the outlook for the injured has been transformed over the last 100 years by the application of scientific medicine. If our young men and women are not to fall prey to the blandishments of quackery they must be led to an understanding of how slowly, carefully and often painfully our present knowledge has been acquired and at least be given the opportunity to add to it.

\section{REFERENCES}

Allen I. V., Kirk J., Maynard R. L., Cooper G. H., Scott R. \& Crockard A. (1983) An ultra structural study of experimental high velocity penetrating head injury. Acta Neuropathologica (Berl) 59, 277-82.

Bull J. P. (1982) Injury severity scoring systems. Injury 14, 2-6.

Gordon D. S. \& Crockard H. A. (1974) Early management of the severe head injury. Proceedings of the Royal Society of Medicine 67, 8-9.

Jackson D. McG. (1979) Burns: McIndoe's contribution and subsequent advances. Annals of the Royal College of Surgeons of England 61, 335-40.

Jackson D. S., Batty C. G., Ryan J. M. \& McGregor W. S. P. (1983) The Falklands War: army field surgical experience. Annals of the Royal College of Surgeons of England 65, 281-5.

MacDonald R. C., Banks J. G. \& Ledingham I. M. A. (1980) Transportation of the injured. Injury 12, 225-33.

MacKay M. (1982) The prevention of injury in road accidents. In Topical Review in Accident Surgery. Tubbs N. \& London P. S. (eds) Bristol, Wright.

Medawar P. (1967) The art of the soluble: creativity and originality in science. London Methuen.

Scott R. (1976) In Projectile trauma-an enquiry into bullet wounds. MCh Thesis, University of Oxford.

Scott R. (1983) Pathology of injury caused by high velocity missiles. Clinics in Laboratory Medicine 3, 2, 273-94.

Received 23 September 1983; accepted for publication 4 November 1983

This paper was presented at the Scientific Meeting of the Emergency Medicine Research Society, 9-10 September, 1983 in York. 